\title{
Comparison of Success Rate and Radiological Bone Loss in Patients with Mini-Implant versus Conventional-Sized Implant Removable Prostheses: A Meta-Analysis
}

\author{
Khaled B. H. Abubaker1, Yuzhou Li², Sheng Yang3* \\ ${ }^{1}$ College of Stomatology, Chongqing Medical University, Chongqing, China \\ ${ }^{2}$ College of Stomatology, Chongqing Medical University, Chongqing Key Laboratory of Oral Diseases and Biomedical Sciences, \\ Chongqing, China \\ ${ }^{3}$ College of Stomatology, Chongqing Medical University, Chongqing Municipal Key Laboratory of Oral Biomedical Engineering of \\ Higher Education, Chongqing, China \\ Email: ${ }^{500283 @ c q m u . e d u . c n ~}$
}

How to cite this paper: Abubaker, K.B.H., Li, Y.Z. and Yang, S. (2021) Comparison of Success Rate and Radiological Bone Loss in Patients with Mini-Implant versus Conventional-Sized Implant Removable Prostheses: A Meta-Analysis. Open Journal of Stomatology, 11, 65-76.

https://doi.org/10.4236/ojst.2021.112006

Received: December 31, 2020

Accepted: February 1, 2021

Published: February 4, 2021

Copyright $\odot 2021$ by author(s) and Scientific Research Publishing Inc. This work is licensed under the Creative Commons Attribution International License (CC BY 4.0).

http://creativecommons.org/licenses/by/4.0/ (c) (i) Open Access

\begin{abstract}
Background: The objective of this meta-analysis was to assess whether miniimplants have added benefit in terms of implants success rate and average bone loss over conventional-sized implants after one year of follow-up. Methods: An electronic search of randomized clinical trials was conducted in MEDLINE (via PubMed), Cochrane Central Register of Clinical Trials (CENTRAL) and Web of Science for studies including complete or partial edentulous patients requiring two or four mini-implants or conventional/ standard-sized implants in the maxilla or mandible for implant-supported removable prostheses who completed 12 months of follow-up. Results: The search provided 194 unique articles which were screened for title and abstract. Screening generated 12 articles which went through full-text analysis using eligibility criteria, and 4 articles were included for meta-analysis. Meta-analysis of these studies indicated a non-significant difference in the success rate between the two interventions ( $\mathrm{OR}=1.69[0.74,3.85 ; \mathrm{p}=0.21])$. Bone loss estimates resulted in a significant bone reduction (Mean Difference $=-0.74[-0.95,-0.53 ; \mathrm{p}<0.05])$ in favor of two mini-implants when compared with two conventional-sized implants, but when compared four miniwith two conventional-sized implants, the estimates were non-significant (Mean Difference $=-0.24[-0.69,0.20 ; \mathrm{p}=0.29])$. Conclusion: The current evidence does not provide solid evidence of the benefits of one intervention over the other. More studies with follow-up times of 10 and more years are needed as
\end{abstract}


current studies have described the short-term outcomes.

\section{Keywords}

Dental Implants, Mini Dental Implants, Conventional Dental Implants, Success Rate, Radiological Bone Loss

\section{Introduction}

In recent years, dental implants have become the predictable treatment option for treatment of missing teeth [1]. They have gained much popularity because of their ability to preserve adjacent tooth structure and bone [2] [3] and due to scientific advances in the field of implant dentistry [4]. For example, in the USA, the prevalence of dental implants among adults with at least one missing tooth increased from $0.7 \%$ in 1999 to $5.7 \%$ in 2016 [5]. Despite its increasing popularity, there are several clinical aspects such as biologic and technical complications that are still debated [4].

Though not conforming to the proposed classification of dental implant length and diameter, as proposed by [6], recent randomized clinical studies embarked to compare clinical outcomes of using mini-implants over conventional-sized implants. Conventional-sized implants are described as those having a diameter ranging from 3.4 to $5.8 \mathrm{~mm}$ [7] while mini-implants as those ranging from 1.8 to 3.3 $\mathrm{mm}$ in diameter and 10 to $15 \mathrm{~mm}$ in length [8]. Mini-implants are considered to be superior to conventional-size implants as they offer less surgical trauma, cost effectiveness, possibility of immediate loading, possibility of use in atrophy edentulous ridge, and the dramatically smaller percutaneous circumference that may reduce the implant exposure to bacterial invasion [7]. However, the actual clinical benefits of mini implants over conventional-sized implants lack adequate evidence.

In 2017, Mostafa and colleagues performed a systematic review and meta-analysis comparing the implant survival, patients satisfaction, marginal bone loss and incidence of fracture between mini-implants and conventional-sized implants [9]. The study did not find strong evidence to support the use of mini-implant over conventional ones. Based on their analyzed parameters, authors suggested that mini dental implants can be used as an alternative choice to conventional dental implant. However, in their analysis, they did not establish comparisons of findings of resonance frequency analysis (RFA)-measure of implant stability, and implants success rates. In addition, their analysis of marginal bone loss did not consider an implant as a unit of measure. Further, they used individual patients regardless of number of implants placed per patient. Therefore, we conducted this meta-analysis to fill-in gaps of knowledge left from the previous analysis by establishing a statistical comparison of clinical outcomes of mini and conventional-sized implants by pooling together RFA outcomes, success rate and marginal bone loss of the two interventions. 


\section{Methods}

\subsection{Eligibility Criteria}

This review considered randomized clinical trials (RCTs) that compare clinical outcomes of using mini-implant and conventional dental implant regardless of whether there was an immediate or delayed loading. After surgical procedure patients should be followed-up for 12 months. At follow-up, patients should go through radiological bone loss measurement on digital periapical or panoramic radiographs and evaluation of implant success rate using criteria developed during Consensus Conference of the International Congress of Oral Implantology in Pisa (ICOI) [10].

\subsection{Search and Data Sources}

A through literature search was conducted and was completed on 19 October 2019. The primary database used was MEDLINE (via PubMed) at https://pubmed.ncbi.nlm.nih.gov/, Cochrane Central Register of Clinical Trials (CENTRAL) and Web of Science. In the PubMed platform, we conducted the search using the search strategy developed by Siva Ramakrishnan and Sridharan [11]. The search strategy was $((((($ implant overdenture [tiab] OR denture* [tiab] OR full denture* [tiab])) AND (implant* [tiab] OR mini-implant* [tiab] OR mini implant ${ }^{\star}$ [tiab] OR narrow implant ${ }^{\star}$ [tiab] OR diameter reduced implant $^{*}$ [tiab])) AND Humans[Mesh])) AND ((randomized [tiab] OR randomized [tiab] OR RCT [tiab] OR clinical trial [tiab]) AND Humans[Mesh])) NOT ((review [pt] OR review [ti] OR meta-analysis [tiab] OR metaanalysis [tiab]) AND Humans[Mesh]). The searches were conducted independently and in duplicate by two authors (K.A. and Y.L). We hand-searched the reference lists of retrieved relevant articles for other relevant articles published in journals that are not indexed in the searched databases. The search was limited to English language.

\subsection{Study Selection}

Article screening and eligibility followed PRISMA 2009 Flow Diagram [12]. Each level of review (Figure 1) was completed in duplicates by two reviews (K.A and Y.L). The two reviewers independently screened titles and abstracts retrieved by the search in accordance with the following inclusion criteria: 1) studies containing completely edentulous patients receiving two or four mini-implants or conventional/standard-sized implants in the maxilla or mandible for implant-supported overdentures; 2) implants placed in the maxilla or mandible with no limitation on technique of placement, loading protocol, or the attachment system used; and 3) patients were followed and outcomes were assessed 12 months post-surgery. A 12 months visit involved recording of ISQ values and digital periapical radiographs as well as assessment of the occlusion, stability, and retention of the prosthesis, patient satisfaction, and overall evaluation. Two 

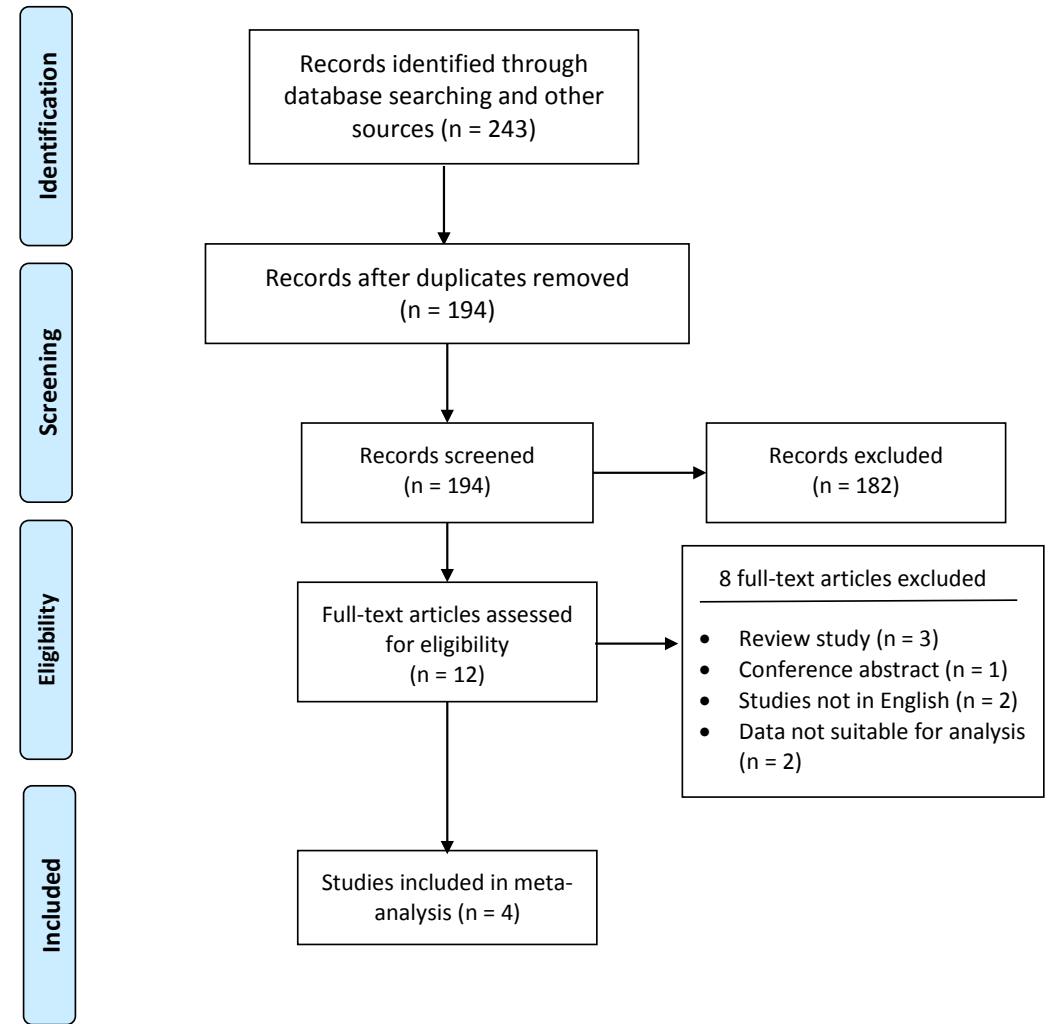

Figure 1. PRISMA flow diagram.

review authors (K.A and Y.L) retrieved full texts and examined for compliance of all potentially eligible studies. We resolved disagreements by discussion.

\subsection{Data Collection and Data Items}

Reviewers designed a form in excel spreadsheet for data extraction. The two reviewers (K.A and Y.L) conducted the data extraction independently. Discrepancies were resolved in a group and after completing data extraction until reaching consensus. The excel spreadsheet captured data in the form of; Study, Study location (country), Study type, Number of patients in each treatment group, Implants success rate (\%), Average radiographic bone level $(\mathrm{mm})$ per study group at one year, Number of recorded prosthetic complications, Patient's satisfaction based on a visual analogue scale (VAS) at one year, resonance frequency analysis (RFA) using the Osstell ${ }^{\circledR}$ ISQ, and risk of bias domains.

\subsection{Assessment of Risk of Bias in Included Studies}

Two reviewers (K.A and Y.L) independently assessed the included studies for risk of bias (RoB) using the Cochrane Risk of bias assessment tool, which addresses the following domains: selection bias (randomization and allocation concealment); performance bias (blinding of participants and personnel); detection bias (blinding of outcome assessors); attrition bias (incomplete outcome data); reporting bias (selective reporting) and other bias. The RoB summary and graphs are summarized in Figure 2 and Figure 3 respectively. 


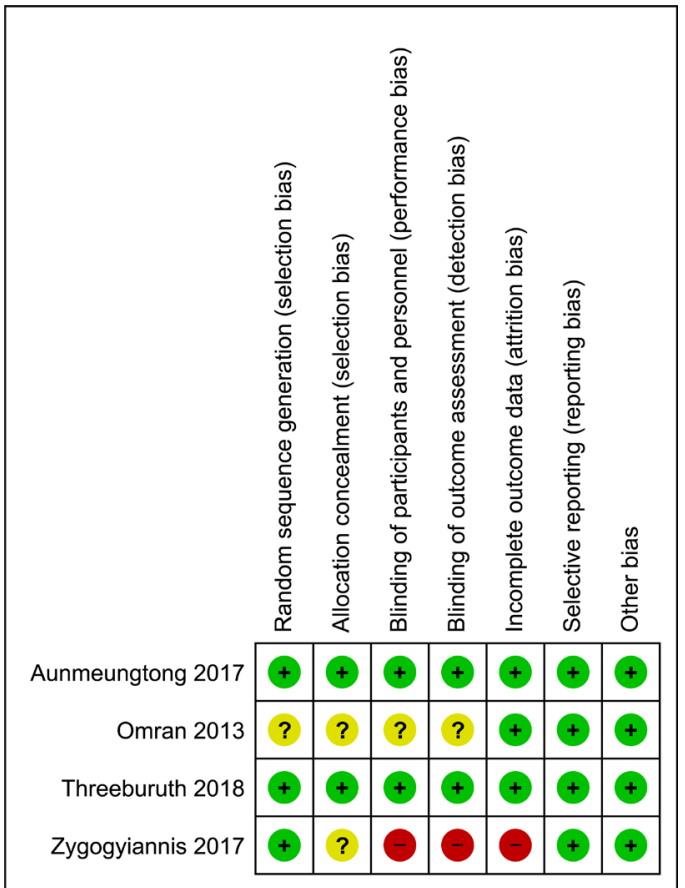

Figure 2. Risk of bias summary.

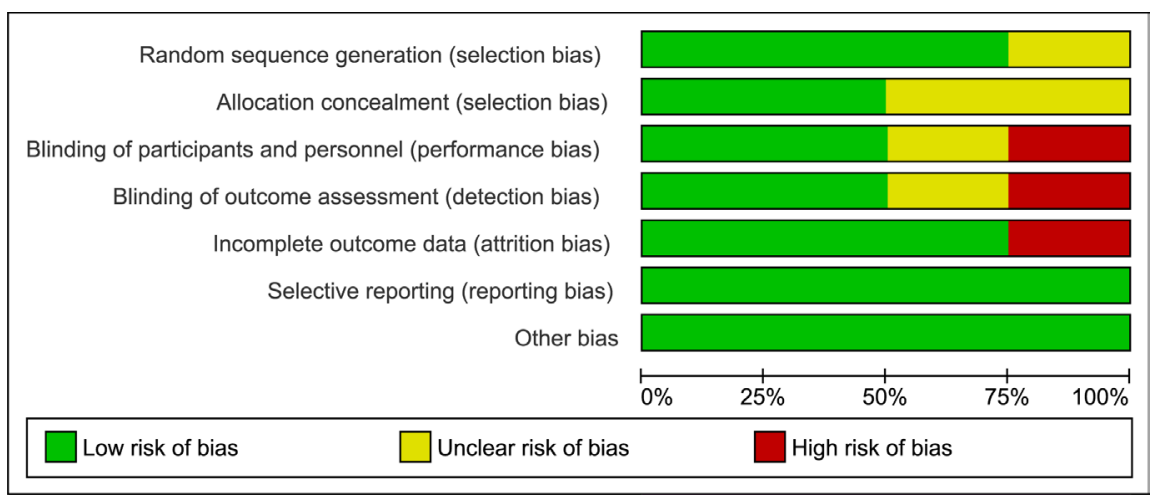

Figure 3. Risk of bias graph across all included studies.

\subsection{Summary Measures and Synthesis of Results}

Meta-analysis was performed using Review Manager (RevMan) Version 5.3 [13]. For dichotomous data (success rate), we used the number of events in the mini-implants and conventional implant groups to calculate Mantel-Haenszel odds ratios (OR). Analysis of continuous data (radiological bone level) was achieved by using the inverse variance of mean difference. Ninety-five percent confidence interval (95\% CI) was used to estimate the precision of the estimated odds ratios and mean differences, and $\mathrm{p}$ value of $<0.05$ was used as a measure of significance. When studies were sufficiently homogeneous $\left(\mathrm{I}^{2} \leq 50 \%\right)$, the data was combined by using a fixed-effect model and when substantial heterogeneity was observed $\left(\mathrm{I}^{2}>50 \%\right)$, a random-effect model would be used. When substantial heterogeneity was detected, possible explanations would be explored using sensitivity analyses. 


\section{Results}

\subsection{Study Selection}

The PRISMA flow chart of the study selection process is presented in Figure 1. The search process brought a total of 194 unique references. After the screening of the titles and abstracts, 12 unique articles were retrieved. Our screening identified no additional studies. After strictly applying the inclusion criteria by reading through the retrieved full texts, 4 studies were eligible for inclusion in the meta-analysis. Excluded studies were 3 review studies, 1 conference abstract, 2 studies were not published in English and 2 studies had findings that do not support meta-analysis. Characteristics of the included studies are summarized in Table 1.

Table 1. Characteristics of included randomized controlled trials.

\begin{tabular}{|c|c|c|c|c|c|c|c|c|}
\hline \multirow{2}{*}{ Study } & \multirow{2}{*}{$\begin{array}{c}\text { Follow-up } \\
\text { period }\end{array}$} & \multirow{2}{*}{$\begin{array}{c}\text { Age } \\
\text { (mean, years) }\end{array}$} & \multirow{2}{*}{ Implant system } & \multicolumn{2}{|c|}{ Implant size (mm) } & \multirow{2}{*}{ Intervention } & \multirow{2}{*}{ Control } & \multirow{2}{*}{ Outcomes } \\
\hline & & & & Mini & Conventional & & & \\
\hline $\begin{array}{c}\text { Aunmeungtong } \\
2017\end{array}$ & 12 months & $\begin{array}{l}\text { Two mini: } \\
69.26 \pm 11.2 ; \\
\text { Four mini: } \\
66.65 \pm 6.28 \\
\text { Conv: } \\
73.8 \pm 10.4\end{array}$ & $\begin{array}{l}\text { PW plus } \\
\text { (Nakhon } \\
\text { Pathom, } \\
\text { Thailand) }\end{array}$ & $\begin{aligned} \mathrm{D} & =3.0 \\
\mathrm{~L} & =12\end{aligned}$ & $\begin{array}{c}\mathrm{D}=3.75 \\
\mathrm{~L}=10\end{array}$ & $\begin{array}{l}40 \text { patients received } \\
\text { immediate loading } \\
\text { of mini-implants } \\
\text { ( } 20 \text { two and } 20 \text { four } \\
\text { implants). }\end{array}$ & $\begin{array}{l}20 \text { patients } \\
\text { received } \\
\text { immediate } \\
\text { loading with two } \\
\text { convention- } \\
\text { al-sized im- } \\
\text { plants. }\end{array}$ & $\begin{array}{l}\text { Implantation } \\
\text { success rate, } \\
\text { radiographic bone } \\
\text { level changes, } \\
\text { prosthodontic } \\
\text { complications } \\
\text { and patient } \\
\text { satisfaction. }\end{array}$ \\
\hline $\begin{array}{l}\text { Threeburuth } \\
2018\end{array}$ & 12 months & $64.1 \pm 5.56$ & $\begin{array}{l}\text { PW plus } \\
\text { (Nakhon } \\
\text { Pathom, } \\
\text { Thailand }\end{array}$ & $\begin{aligned} \mathrm{D} & =3.0 \\
\mathrm{~L} & =12\end{aligned}$ & $\begin{array}{c}\mathrm{D}=3.75 \\
\mathrm{~L}=10\end{array}$ & $\begin{array}{l}15 \text { patients received } \\
\text { immediate loading of } \\
\text { two mini-implants. }\end{array}$ & $\begin{array}{l}15 \text { patients } \\
\text { received } \\
\text { immediate } \\
\text { loading of two } \\
\text { conventional } \\
\text { dsized implants. }\end{array}$ & $\begin{array}{l}\text { Radiographic } \\
\text { bone loss, patient } \\
\text { satisfaction and } \\
\text { implantation } \\
\text { success rate. }\end{array}$ \\
\hline $\begin{array}{l}\text { Zigogiannis } \\
2017\end{array}$ & 12 months & $67.9 \pm 7.7$ & $\begin{array}{l}\text { Straumann } \\
\text { implants, } \\
\text { Isntitut } \\
\text { Straumann }\end{array}$ & $\begin{array}{c}\mathrm{D}=1.8 \\
2.1 \text { or } 2.4 \\
\mathrm{~L}=10-18 \\
\quad \text { (range) }\end{array}$ & $\begin{array}{l}\mathrm{D}=3.3 \text { or } 4.1 \\
\mathrm{~L}=10 \text { or } 12\end{array}$ & $\begin{array}{l}25 \text { patients received } \\
\text { immediate loading of } \\
\text { four mini-implants. }\end{array}$ & $\begin{array}{l}15 \text { patients } \\
\text { received } \\
\text { immediate and } \\
10 \text { received } \\
\text { delayed loading } \\
\text { of two } \\
\text { standard-sized } \\
\text { tissue-level } \\
\text { implants. }\end{array}$ & $\begin{array}{l}\text { Marginal bone } \\
\text { loss, success and } \\
\text { survival rates. }\end{array}$ \\
\hline Omran 2013 & 12 months & Not available & $\begin{array}{c}\text { Sendax MDI } \\
\text { MAX; IMTEC, } \\
\text { Corp., Ardmore, } \\
\text { USA) and } \\
\text { Tapered Internal } \\
\text { dental implant } \\
\text { system, } \\
\text { Biohorizons } \\
\text { Co., USA }\end{array}$ & $\begin{array}{l}\mathrm{D}=1.8 \\
\mathrm{~L}=15\end{array}$ & Normal sized & $\begin{array}{l}7 \text { patients received } \\
\text { immediate loading of } \\
\text { four mini-implants } \\
\text { mandibular } \\
\text { overdentures } \\
\text { opposing a maxillary } \\
\text { complete denture }\end{array}$ & $\begin{array}{l}7 \text { patients } \\
\text { received } \\
\text { immediate } \\
\text { loading of two } \\
\text { ball attachments } \\
\text { carried on two } \\
\text { normal-sized } \\
\text { implants. }\end{array}$ & $\begin{array}{l}\text { Marginal bone } \\
\text { height changes. }\end{array}$ \\
\hline
\end{tabular}

Abbreviations: $\mathrm{D}=$ diameter; $\mathrm{L}=$ length. 


\subsection{Resonance Frequency Analysis (RFA) Analysis}

Two studies [7] [14] performed and reported implant stability measurement using the Osstell ${ }^{\circledR}$ implant stability quotient (ISQ) after one year-follow up. In a study by Threeburuth and colleagues, the ISQs increased from $68.3 \pm 2.94 \mathrm{im}$ mediately after mini-implant placement to $70.3 \pm 2.42$ twelve months after implant placement. For the conventional-sized implants, the ISQs changed from 77 \pm 2.35 immediately after implant placement to $77.6 \pm 1.90$ twelve months later [7].

On the other hand, Aunmeungtong et al., 2017 found that after one year-follow up, the lowest mean ISQ score was 66.0 which was recorded in patients with four mini-implants; the highest mean ISQ score was 79.0 in patients with two conventional-sized implants [14]. Data provided by the studies was not sufficient to run a meta-analysis, however statistical analyzes in both studies showed no statistically significant differences in the mean ISQ score between mini and conventional-sized implants.

\subsection{Pooled Results}

\section{Success rate of mini- versus conventional dental implants}

Three studies [7] [14] [15] with a total of 250 surgically placed implants using either mini or conventional-sized implants were used to compare the success rate of two treatment modalities. A non-significant pooled odds ratio of 1.69 $[0.74,3.85 ; \mathrm{p}=0.21]$ was observed suggesting that statistically, none of the treatment modality is superior to the other (Figure 4). Regarding the number of implants per patient, in all studies patients were placed with two conventional-sized implants. For the mini-implants, in two studies [14] [15] patients were placed with four implants and in one study [7] patients were placed with two implants. Comparison of success rate in relation to the number of implants per patient did not provide statistically different findings.

Changes in radiological peri-implant bone level

The radiological peri-implant bone level of mini-implants was compared with conventional-sized implants. Two studies [7] [14] involving a total of 140 surgically placed dental implants compared bone loss to patients who were treated with two mini-implants as compared to two conventional-sized implants. The estimates provided a significant mean bone reduction $-0.74[-0.95,-0.53 ; \mathrm{p}<$ $0.05]$ in favor of two mini-implants (Figure 5).

Three studies [14] [15] [16] with a total of 252 surgically placed implants compared bone loss in patients who were treated with four mini-implants as compared to two conventional-sized implants. A non-significant pooled mean difference of $-0.24[-0.69,0.20 ; \mathrm{p}=0.29]$ was observed, suggesting that statistically, none of the treatment modality is superior to the other (Figure 6). However, we detected substantial heterogeneity $\left(\mathrm{I}^{2}=95 \%\right)$ but sensitivity analysis (done by removing one study at a time) did not result into any significant estimates (Figures $7(\mathrm{~A})-(\mathrm{C})$ ). 


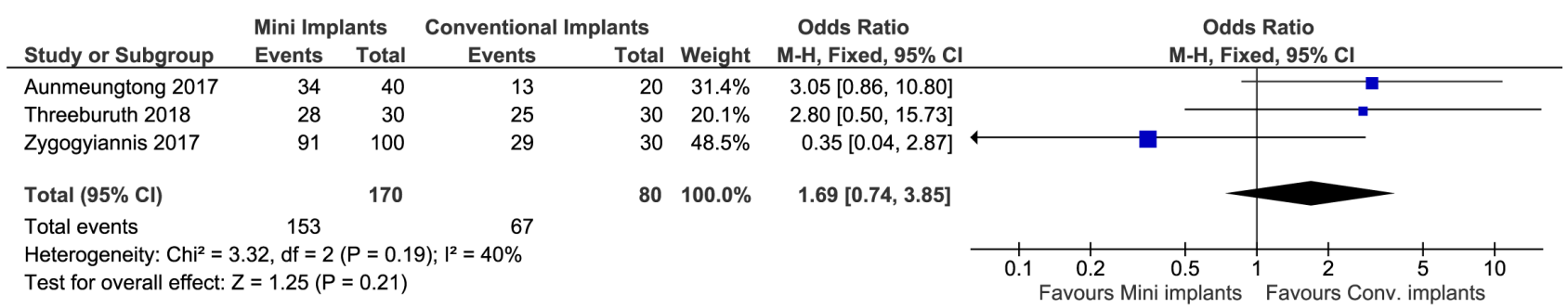

Figure 4. Forest plot of dental implants success rate. The success rate of mini- was compared with conventional-sized implants and a statistically non-significant effect was observed $(\mathrm{p}=0.21)$.

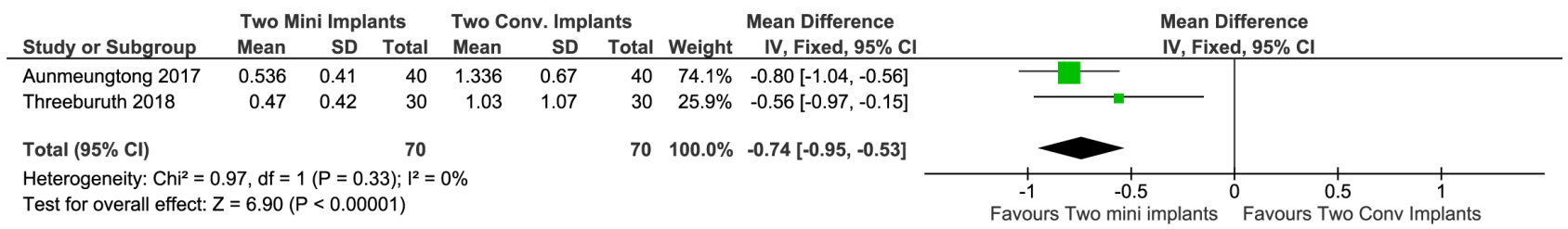

Figure 5. The radiological bone loss of two mini- was compared with two conventional-sized implants and a statistically significant effect was observed $(\mathrm{p}<0.05)$.

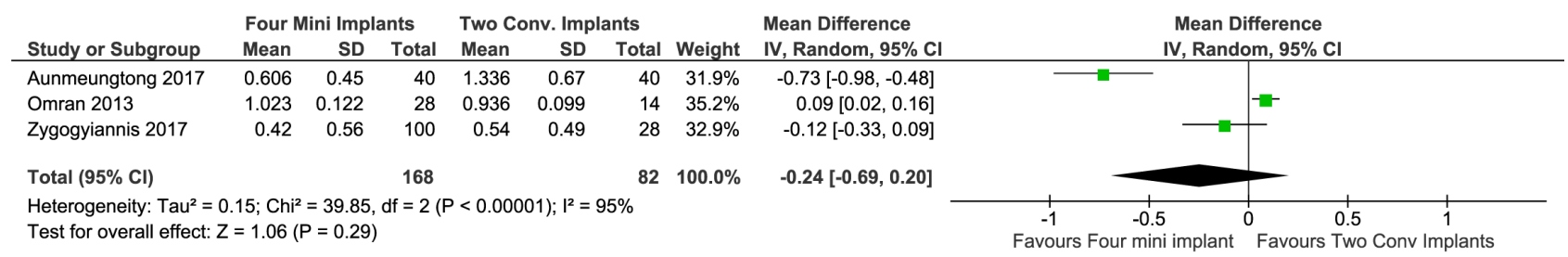

Figure 6. The radiological bone loss of four mini- was compared with two conventional-sized implants and a statistically non-significant effect was observed $(\mathrm{p}=0.29)$.

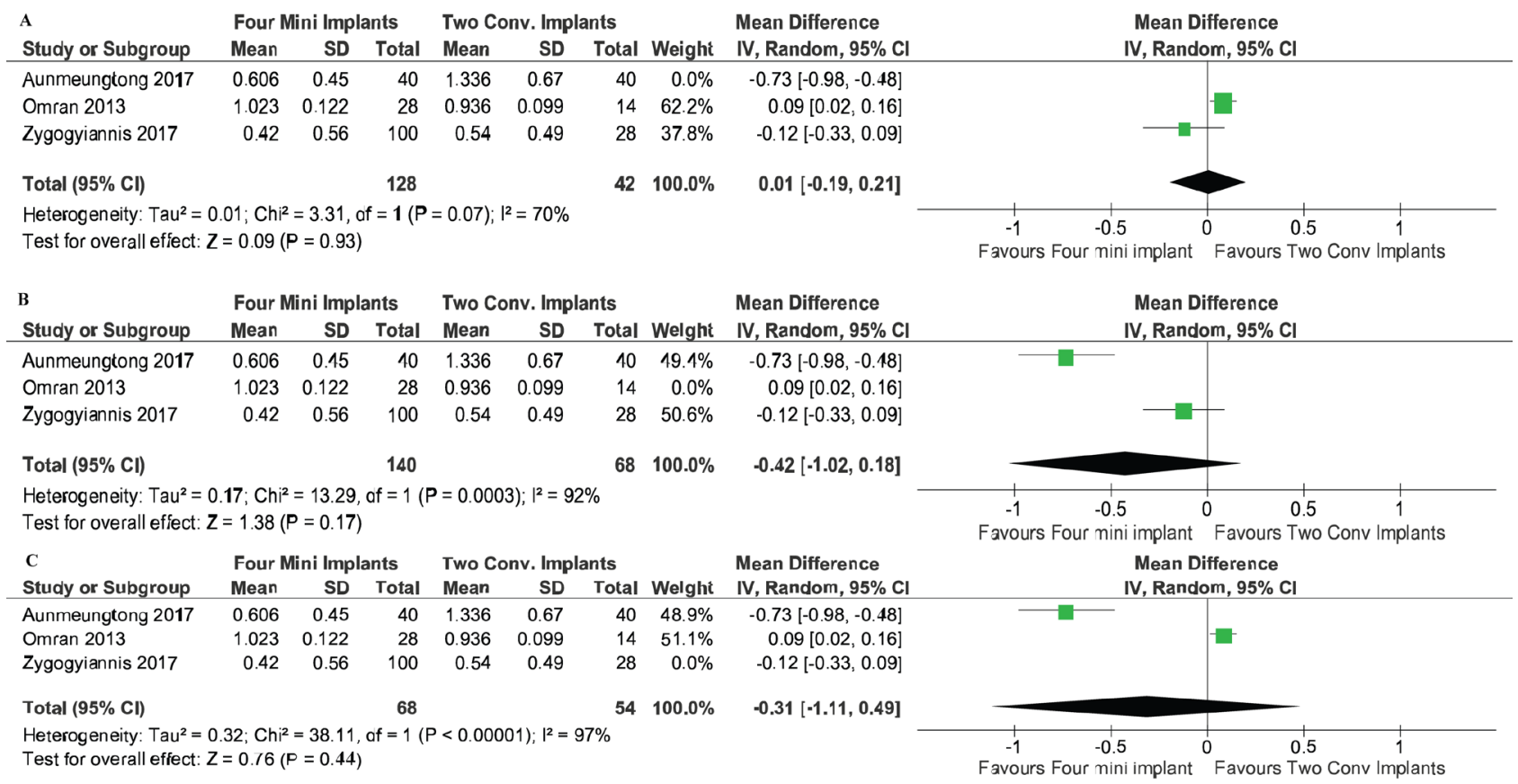

Figure 7. Sensitivity analysis of the radiological bone loss findings of four mini- was compared with two conventional-sized implants. Despite removal of first (A), second (B) and third (C) study at a time did not result into statistically significant outcome. 


\subsection{Prosthetic Complications}

Two studies [14] [15] reported prosthetic complications that occurred within one year after surgical treatment. Aunmeungtong, et al. documented a total of 64 prosthetic complications from 40 patients placed with mini-implants. In patients who received conventional-sized dental implants $(n=20)$, a total of 52 prosthetic complications were recorded [14]. In the course of one year, Zygogyiannis and colleagues reported a total of 30 complications from 25 patients with mini-implants, and a total of 25 complications from 14 patients with conventional-sized implants [15]. The available information is not enough to establish association between the two types of implants.

\section{Discussion}

This meta-analysis merged data to compared implants success rate and radiological peri-implant bone loss between patients placed with mini-implants and those placed with conventional-sized implants. There was no clear evidence of a difference in success rate between the two interventions after one year of follow-up. In the annual radiological bone loss evaluation, we observed a statistically significant mean bone reduction when two mini-implants were compared to two conventional-sized implants but when four mini-implants were compared with two conventional-sized implants the outcomes were non-significant. Included studies did not offer adequate data to compare RFA outcomes and occurrence of prosthetic complications between the two interventions.

Mini-implants have been reported to be superior to conventional-sized implants in terms of the benefits they offer to patients [7]. Due to their reduced diameter (diameter less than 3), Mini-implants offer high survival rates, immediate stability, less postoperative discomfort, favorable marginal bone loss, and increased satisfaction and quality of life of patients. Overdentures retained with conventional-sized implants offer good long term results, but are also associated with high cost and difficulty with placing especially in situations where there is reduced buccolingual dimensions of bone [17]. However, the current analysis did not find out significant outcome to prove these benefits, maybe, due to short follow-up duration.

Comparing clinical outcomes after one year of follow-up for bone loss seems to be not long enough because it is mainly accepted that crestal bone loss of dental implants during the first year of loading is an inevitable phenomenon and is generally looked upon as an adaptive response to surgical trauma and loading [18]. After the first year, an extensive bone loss might be generally due to an exacerbation of adverse body reactions caused by non-optimal implant components or prosthodontics and/or compromised patient factors [19]. To better compare clinical significance of mini and conventional-sized implants-after being placed by properly trained personnel-follow-up assessment should be done after 10 or more years [4] [19].

Mini-implants have achieved a success rate of up to $97.2 \%$ [20] but this does 
not make them superior to conventional-sized implants because in this analysis both implants showed almost similar success rate $(\mathrm{OR}=1.69[0.74,3.85 ; \mathrm{p}=$ $0.21])$. In addition, as compared to complete dentures, overdentures are associated with increased biting forces [21] [22] but there is no difference in biting force between the two types of implants [21]. There might be other risk factors which might be linked to implants failure which are not related to implant size. In addition, even individual genetic disparities do not indicate an increased risk for implant failure [23]. Risk factors documented to play an important role in the success rate of dental implants include cigarette smoking, bruxism, diabetes and bone augmentation [24]. Therefore, if implants are placed by well-trained personnel the success rate is independent on the type or size of the implant.

This review has some limitations. First, the review managed to acquire only four studies that meet the inclusion criteria providing inadequate evidence. Among the included studies, three reported success rate, two compared radiological bone loss between patients with two mini-implants against two conventional-sized implants. These analyses are not adequate to offer a sound statistical comparison. Therefore, the findings should be analyzed with caution. Second, the review could not find any study that compared radiographic outcomes in patients with four mini and four conventional-sized dental implants. Considering the advantages of mini-implants, more high-quality randomized controlled trials comparing mini with standard diameter implants are required.

In conclusion, available evidence comparing clinical outcomes of mini and conventional-sized dental implants do not provide confidence results due to their short follow-up period. In the current analysis, little amount of evidence is available and do not offer added clinical advantage of mini- over conventional-sized implants. More studies with follow-up times of 10 and more years are needed.

\section{Acknowledgements}

YZ.L is supported by the Natural Science Foundation of Chongqing (Grant No. cstc2019jcyj-bshX0005). S.Y is supported by the Scientific and Technological Research Program of Chongqing Municipal Education Commission (Grant No. KJQN201900441).

\section{Conflicts of Interest}

All authors declare no conflict of interest.

\section{References}

[1] Pjetursson, B.E., Tan, K., Lang, N.P., Brägger, U., Egger, M. and Zwahlen, M. (2004) A Systematic Review of the Survival and Complication Rates of Fixed Partial Dentures (FPDs) after an Observation Period of at Least 5 Years: I. Implant-Supported FPDs. Clinical Oral Implants Research, 15, 625-642. https://doi.org/10.1111/j.1600-0501.2004.01117.x

[2] Battle-Siatita, S.O., Bartoloni, J.A., Hancock, R.H. and Chong, C.H. (2009) Retros- 
pective Analysis of Dental Implants among United States Air Force Basic Military Trainees. Military Medicine, 174, 437-440.

https://doi.org/10.7205/MILMED-D-02-5008

[3] Jivraj, S. and Chee, W. (2006) Rationale for Dental Implants. British Dental Journal, 200, 661-665. https://doi.org/10.1038/sj.bdj.4813718

[4] Buser, D., Sennerby, L. and De Bruyn, H. (2017) Modern Implant Dentistry Based on Osseointegration: 50 Years of Progress, Current Trends and Open Questions. Periodontol 2000, 73, 7-21. https://doi.org/10.1111/prd.12185

[5] Elani, H.W., Starr, J.R., Da Silva, J.D. and Gallucci, G.O. (2018) Trends in Dental Implant Use in the U.S., 1999-2016, and Projections to 2026. Journal of Dental Research, 97, 1424-1430. https://doi.org/10.1177\%2F0022034518792567

[6] Al-Johany, S.S., Al Amri, M.D., Alsaeed, S. and Alalola, B. (2017) Dental Implant Length and Diameter: A Proposed Classification Scheme. Journal of Prosthodontics, 26, 252-260. https://doi.org/10.1111/jopr.12517

[7] Threeburuth, W., Aunmeungtong, W. and Khongkhunthian, P. (2018) Comparison of Immediate-Load Mini Dental Implants and Conventional-Size Dental Implants to Retain Mandibular Kennedy Class I Removable Partial Dentures: A Randomized Clinical Trial. Clinical Implant Dentistry and Related Research, 20, 785-792. https://doi.org/10.1111/cid.12646

[8] Flanagan, D. and Mascolo, A. (2011) The Mini Dental Implant in Fixed and Removable Prosthetics: A Review. Journal of Oral Implantology, 37, 123-132. https://doi.org/10.1563/AAID-JOI-D-10-00052.1

[9] Mostafa, M.H., Alsourori, A.A., Kaddah, A.F. and Fayyed, A.E. (2017) Mini-Implant-Versus Conventional Implant-Retained Mandibular Overdenture in Completely Edentulous Patient: A Systematic Review and Meta-Analysis. International Journal of Advanced Research, 5, 992-1002. http://dx.doi.org/10.21474/IJAR01/5858

[10] Misch, C.E., Perel, M.L., Wang, H.L., Sammartino, G., Galindo-Moreno, P., Trisi, P., et al. (2008) Implant Success, Survival, and Failure: The International Congress of Oral Implantologists (ICOI) Pisa Consensus Conference. Implant Dent, 17, 5-15.

[11] Sivaramakrishnan, G. and Sridharan, K. (2017) Comparison of Patient Satisfaction with Mini-Implant versus Standard Diameter Implant Overdentures: A Systematic Review and Meta-Analysis of Randomized Controlled Trials. International Journal of Implant Dentistry, 3, Article No. 29. https://doi.org/10.1186/s40729-017-0092-4

[12] Moher, D., Liberati, A., Tetzlaff, J., Altman, D. and The PRISMA Group (2009) Preferred Reporting Items for Systematic Reviews and Meta-Analyses: The PRISMA Statement. PLoS Medicine, 6, e1000097. https://doi.org/10.1371/journal.pmed.1000097

[13] The Cochrane Collaboration (2014) Review Manager (RevMan) [Computer program]. Version 5.3.5. The Nordic Cochrane Centre, The Cochrane Collaboration, Copenhagen

[14] Aunmeungtong, W., Kumchai, T., Strietzel, F.P., Reichart, P.A. and Khongkhunthian, P. (2017) Comparative Clinical Study of Conventional Dental Implants and Mini Dental Implants for Mandibular Overdentures: A Randomized Clinical Trial. Clinical Implant Dentistry and Related Research, 19, 328-340. https://doi.org/10.1111/cid.12461

[15] Zygogiannis, K., Aartman, I.H.A., Parsa, A., Tahmaseb, A. and Wismeijer, D. (2017) Implant Mandibular Overdentures Retained by Immediately Loaded Implants: Clinical and Radiographic Outcomes between. The International Journal of Oral \& 
Maxillofacial Implants, 32, 1377-1388. https://doi.org/10.11607/jomi.5981

[16] Omran, M., Abdelhamid, A. and Elkarargy, A. (2013) Mini-Implant Overdenture versus Conventional Implant Overdenture (A Radiographic and Clinical Assessments). The Journal of American Science, 9, 89-97.

[17] Upendran, A., Gupta, N. and Salisbury, H.G. (2020) Dental Mini-Implants. StartPearls. https://www.ncbi.nlm.nih.gov/books/NBK513266/

[18] Adell, R., Lekholm, U., Rockler, B. and Brånemark, P.I. (1981) A 15-Year Study of Osseointegrated Implants in the Treatment of the Edentulous Jaw. International Journal of Oral Surgery, 10, 387-416. https://doi.org/10.1016/S0300-9785(81)80077-4

[19] Albrektsson, T., Chrcanovic, B., Östman, P.-O. and Sennerby, L. (2017) Initial and Long-Term Crestal Bone Responses to Modern Dental Implants. Periodontol 2000, 73, 41-50. https://doi.org/10.1111/prd.12176

[20] Park, J.-H., Shin, S.-W. and Leea, J.-Y. (2018) Two-Step Immediate Loading of Mandibular Overdentures Retained by Mini-Implants: A Prospective Clinical Study. International Journal of Prosthodontics, 31, 446-450.

https://doi.org/10.11607/ijp.5776

[21] Hasan, I., Madarlis, C., Keilig, L., Dirk, C., Weber, A., Bourauel, C., et al. (2016) Changes in Biting Forces with Implant-Supported Overdenture in the Lower Jaw: A Comparison between Conventional and Mini Implants in a Pilot Study. Annals of Anatomy-Anatomischer Anzeiger, 208, 116-122.

https://doi.org/10.1016/j.aanat.2016.06.011

[22] Lohmann, A., Keilig, L., Heinemann, F., Bourauel, C. and Hasan, I. (2019) Numerical Investigation of Complete Mandibular Dentures Stabilized by Conventional or Mini Implants in Patient Individual Models. Biomedizinische Technik/Biomedical Engineering, 64, 103-110. https://doi.org/10.1515/bmt-2017-0137

[23] Santiago Jr., J.F., Biguetti, C.C., Matsumoto, M.A., Kudo, G.A.H., da Silva, R.B.P., Saraiva, P.P., et al. (2018) Can Genetic Factors Compromise the Success of Dental Implants? A Systematic Review and Meta-Analysis. Genes, 9, Article No. 444. https://doi.org/10.3390/genes9090444

[24] Kandasamy, B., Kaur, N., Tomar, G.K., Bharadwaj, A., Manual, L. and Chauhan, M. (2018) Long-Term Retrospective Study Based on Implant Success Rate in Patients with Risk Factor: 15-Year Follow-Up. Journal of Contemporary Dental Practice, 19, 90-93. https://doi.org/10.5005/jp-journals-10024-2217 